\title{
Virtual nanoworlds for learning
}

J ennifer Flint, Karljohan Lundin Palmerius, Gunnar Höst and Konrad Schönborn

\section{Book Chapter}

Cite this chapter as:

Flint, J ., Lundin, K., Höst, G., Schönborn, K. Virtual nanoworlds for learning, In D., K. (eds), Virtual Nanoworlds for Learning, Boca Raton: CRC Press; 2020, pp. 7-1-714. ISBN: 9780429351631

DOI: https:// doi.org/ 10.1201/9780429351631

21st Century Nanoscience, , No. 10

Copyright: CRC Press

https://www.routledge.com/

The self-archived preprint version of this chapter available at Linköping University Institutional Repository (DiVA):

http:// urn.kb.se/ resolve?urn=urn:nbn:se:liu:diva-171595 


\title{
VIRTUAL NANOWORLDS FOR LEARNING
}

\author{
Jennifer Flint, Karljohan Lundin Palmerius, Gunnar Höst, Konrad Schönborn* \\ Department of Science and Technology (ITN), Linköping University, Campus Norrköping, Sweden \\ *Contact author: konrad.schonborn@liu.se
}

\begin{abstract}
The rapid development of $21^{\text {st }}$ century nanoscience calls for the urgent promotion of both nano-skilled scientists and a nano-literate citizenry. However, the conceptual and cognitive challenges of accessing the counterintuitive and imperceptibly small nanoscale remain a significant barrier for learning and understanding. In response to these challenges, emerging nano education research in the last 10-15 years has seen the development and application of interactive visualization as a means for learners to explore nanoscientific principles. In this chapter, we first present selected examples of interactive visualization environments applied to teach nano-concepts in educational contexts. Secondly, we describe our findings from an educational study on students' interactions with a gesture-based immersive virtual nanoworld. Thirdly, we provide readers with access to a personal computer-based version of the studied virtual nanoworld and offer examples for how the content and features of the interactive simulation can be used as a nano education tool in the classroom.
\end{abstract}

\section{Keywords:}

Nano education; Interactive visualization; Virtual reality; NanoSim; Case study; Nanoconcepts

\section{Introduction and Aims}

Nanoscience and nanotechnology (together referred to as nano) continues to develop swiftly with direct implications for society and the future of humankind. Rising to the demands of $21^{\text {st }}$ century nano requires an ongoing need to develop nano-skills across various levels of formal education, and an obligation to communicate nano to the public in informal educational settings (e.g. Winkelmann 2016). However, providing students and the public with meaningful cognitive opportunities to discover the nanoscopic world, which exhibits unexpected and counterintuitive properties completely divorced from our everyday macroscopic experiences, is a substantial educational undertaking. Nevertheless, nano is a truly convergent science and can be applied as an interdisciplinary pedagogical agent for learners to connect traditionally separated science subjects. Furthermore, nano phenomena can act as a catalyst (Healy 2009) for exciting learners and citizens about science and technology. Recently unfolding research in nano education suggests that one vehicle for accessing and communicating otherwise imperceptible and complex nanoscale structures and processes is through interactive visualization (e.g. Schönborn et al. 2016a, Xie and Lee 2012). The objective of this chapter is to:

- Describe how interactive visualization environments can be used to learn and teach nanoscience in formal and informal contexts.

- Present results from a case study with upper-secondary school students' use of an interactive virtual nanoworld.

- Provide access to an interactive computer-based nano simulation for teachers to expose core nano-concepts to students in the classroom. 


\section{Interactive Visualization as Tool for Learning and Teaching Nano}

\subsection{Visualization as a bridge between the invisible nanoworld and our sensory experiences}

Development of nano literacy in students and the public emerges from developing an understanding of the unique behaviour of matter at the nanoscale (Laherto 2010). In turn, a nano-literate public requires a scientific basis upon which to gauge the perceived benefits and risks of nano for society. However, gaining knowledge of the domination of adhesive forces over gravity and interpreting the relative sizes of objects comprising the nanoworld are cognitively demanding endeavours. Modelling, visualizing and representing nanoscopic structures and processes provide the bridge between the invisible nanoscale and our subsequent perceptions. Hence, visualization methods and tools are crucial for communicating, conceptualizing and understanding nano (Goodsell 2006). The significance of models, simulations and visualization for nano education is also captured in the "big ideas" of nano synthesised by Stevens et al. (2009).

Interactive visualization technology can provide various opportunities for learning and teaching nano. Herein, interactive visualizations provide the possibility for users to drive knowledge construction through their own actions. By actively linking perception and action through manipulation of multimodal interfaces, nanobjects and processes can be visualized through multisensory learning experiences. This approach is supported by an embodied cognition perspective, which argues that the acquisition of scientific knowledge is closely intertwined with our sensorimotor experiences in the world (Amin et al. 2015).

\subsection{Accessing the nanoworld through different interactive visualization systems}

Interactive visualizations are computer-based representations of models or data that allow users to explore nano concepts and principles. The technological components of interactive visualizations can be configured to provide various display, sensory and interactive experiences. A recent systematic review of the literature by Schönborn et al. (2016b) has described the following five overall categories of interactive visualization environments for communicating nano-related knowledge in formal and informal education contexts.

Advances in computer processing capacities have provided multiple computational modelling capabilities in the form of interactive visual simulations for application in nano education. One such simulation, called the Molecular Workbench (MW) and developed by Xie et al. (2011), is a digital interactive environment that integrates various modelling tools for learners to explore processes such as self-assembly. Another example of interactive simulations that can be used to engage nano ideas such as molecular motors have been developed by the Physics Educational Technology (PhET) project. Lastly, an open-access platform provided by the Network for Computational Nanotechnology is called nanoHUB.org and provides various nano-related simulations for potential educational use. Another form of interactive visualization for exploring nano are virtual world and game-based environments. In this regard, the interactive virtual world Second Life has been adapted for learning about nano (McWhorter and Lindhjem 2013), while Nanoquest 3D (Blonder and Sakhnini 2012) is a game aimed at getting students to engage with nanoscale construction tasks.

A further form of interactive visualization that has been applied in nano education interventions are microscope probe-based multisensory platforms. Environments such as the nanoManipulator (Jones et al. 2003) allow learners to explore nanoscopic samples (such as a virus surface) through atomic force microscopy (AFM) while at the same time, receiving 3D visual as well as haptic feedback outputted through a haptic device. In continuation of engaging sensory modalities other than vision, visuohaptic virtual and augmented reality desktop environments offer access to the nanoworld by combining force and visual feedback. 
Within this category of interactive visualization, research in our own group has concerned development and use of an immersive visuohaptic desktop system for students to explore the strength and direction of the electrostatic fields associated with molecules (Höst et al. 2013). Finally, an example of an augmented reality environment that superpositions visual information on to hand-held physical models for exploring 3D properties of molecular surfaces has been developed by Gillet et al. (2005).

Other work in our group has also involved contributing to a fifth category of interactive visualization: gesture-based immersive virtual environments for communicating nano to students and the public (Lundin Palmerius et al. 2012, Schönborn et al. 2014). The NanoSim virtual environment (Figure 1) simulates nanoscale interactions while users engage bodily movements in the form of hand gestures to interact with 3D nano-objects, and thereby gain access to otherwise imperceptible nanoscale structures and processes. NanoSim integrates 3D TV technology and motion tracking through a Microsoft Kinect. See Lundin Palmerius et al. (2012) for details about the technical development of the system.

Please insert Figure 1 about here

FIGURE 1 The NanoSim gesture-based immersive virtual nanoworld developed for pupils and citizens to access and explore nanoscale interactions. Nanotubes are visualized in immersive 3D using a head-coupled perspective to enhance the sense of presence. The user deploys a "grab" hand gesture (a green circle is generated upon successful gesture generation and subsequent contact with a respective virtual nanotube) to move, pull and push the 3D nano-objects. (Photo courtesy of Thor Balkhed/Linköping University).

Two interactive scenarios in the simulated nanoworld provide access to various underpinning nano concepts, where each scenario is framed within opposite ends of a "risk" (nano-toxicity) and "benefit" (nano-therapy) continuum. Regarding the risk interactive scenario, pulling nanotubes apart, and viewing them aggregate again, serves as the basis for understanding the adhesive "sticky" forces that arise due to huge surface area-to-volume ratios at the nanoscale. Macroscopic application of this knowledge (e.g. huge length-todiameter ratios) allows for perception of the potential toxic hazards of industrial nanotube production (lung damage akin to asbestos toxicity). Regarding the benefit interactive scenario, investigating the binding process of modified nanotubes to receptors on a cancer cell surface, serves as the basis for understanding aspects of binding dynamics and that nano-objects are in constant flux. Macroscopic application of this knowledge (e.g. applying infrared radiation will heat specifically bound nanotubes) allows for perception of the potential therapeutic benefits of nano (highly localised destruction of cancer tumours).

Overall, NanoSim consists of nine sequenced "scenes" that can be traversed bidirectionally with virtual "continue" or "back" buttons. The nano-toxicity and nano-therapy gesture-based interactive scenarios are integrated as scene 5 and 8, respectively. See Schönborn et al. (2014) for a complete description of the system content. From a nano education perspective, it is hypothesised that interacting with NanoSim can serve as a basis for building knowledge about nano concepts and principles, and for providing a scientific baseline upon which to judge the potential benefits and risks of nano. 


\section{Case Study of a Gesture-Based Virtual Nanoworld to Expose Students to Nano}

Emanating from the backdrop above, and serving as an example of investigating the role of an interactive virtual learning environment for nano education, this chapter section presents a case study on high school students' interactions with NanoSim (Figure 1). The study posed the following research questions:

1. What cognitive and learning dimensions are afforded by students' interaction with the environment?

2. To what extent are students' attitudes towards the potential benefits and risks of nanotechnology influenced by interaction with the virtual environment?

3. How usable is the interactive virtual environment from a student-user perspective?

\subsection{Theoretical underpinnings: Attitudes to nano, system usability, and affordances of interactive virtual environments in nano education}

Attitudes are defined as an individual's proneness to a specific action or reaction regarding a given issue (McNemar 1946). Studies on attitudes toward nano include dimensions such as benefit and risk (Bainbridge 2002, Gardner et al. 2010), hopefulness and worry (Cobb and Macoubrie 2004), level of interest and disinterest (Dyehouse et al. 2008), and demands for a nano skilled and non-skilled workforce (Murcia 2013). Individuals with higher education levels tend to assign more perceived benefits than risks to nano (e.g. Lee et al. 2005, Lin et al. 2012). At the same time, direct experience generates attitudes that are more confident and consistent with future behaviour (Fazio and Zanna 1981, Hendrick et al. 2013). When it comes to interacting with virtual environments to engage nano, usability is essential to user-centered design (Norman 1999). Usability studies are paramount to identifying interactions and tasks (Bowman et al. 2002) that may potentially detract from intended learning goals.

Cognitive (Hartson 2003) and educational affordances (Bower 2008) support knowing and learning about a phenomenon. Interaction with virtual objects can be considered an educational affordance if the interaction enriches conceptual understanding of the intended content. For example, medical students' interaction with virtual cadavers can impart an understanding of the complexity and integration of human systems. Cognitive affordances of $3 \mathrm{D}$ virtual learning environments can facilitate knowledge of a specific domain, experiential learning (Kiili 2005) that is otherwise impossible to explore first-hand, motivation and engagement, and improved transfer of knowledge and skills to real situations (Dalgarno and Lee 2010). Learning is certainly not a de facto outcome of employing technology in the classroom. However, educational tasks afforded by interaction with visualization environments may result in learning, or the enhancement thereof.

This case study explored three theoretical perspectives related to students' interaction with NanoSim. Firstly, from an external cognition (Scaife and Rogers 1996) perspective, interaction with NanoSim could potentially reduce mental effort by off-loading cognitive processing onto the environment. Hence, actions such as external re-representation (using different forms of external representations for the same concept to make interpretation easier), afford mental support for processing connections between external and internal representations (Liu and Stasko 2010). Secondly, motoric experiences may aid the construction of abstract concepts (Wilson 2002), such as scientists' transformations of interactive virtual protein models into embodied objects relayed via gestures and body contortions (Myers 2008). Thirdly, visualization can support students' understanding of the "unseen" (Kozma et al. 2000) such as the nanoworld. 


\subsection{Methods}

In response to the research questions, a suite of multiple data collection and analysis methods were deployed that included written pre-/post questionnaires, video-captured semi-structured interviews, and a usability web survey. The instruments were piloted in the fall of 2012 (Schönborn et al. 2014) and refined before implementation in the current study.

\subsubsection{Data collection}

Six female and four male $(\mathrm{n}=10)$ upper secondary chemistry Swedish students (aged 16-20) voluntarily participated in the study. One week prior to an interactive session with NanoSim, and directly following the experience, each student answered written pre-/postquestionnaires. These consisted of three open-ended questions and 19 visual analysis scale (VAS) items. The open-ended questions were designed to elicit student's exposure to nano and their attitudes towards its risks and benefits (e.g., Bainbridge 2002, Cobb and Macoubrie 2004, Lin et al. 2012, Siegrist et al. 2007). The VAS is a line with the dichotomous choices of "disagree" at one end and "agree" at the other, or "risky" and "beneficial", respectively. Participants mark their position on the line with an "X" (Murcia 2013).

Video-recorded semi-structured think-aloud interviews (Derry et al. 2010) were conducted while students interacted with NanoSim that was installed as part of an exhibition at Visualization Center C in Norrköping, Sweden. The interview protocol was designed as a series of questions concerning students' initial observations of the system followed by interactive tasks related to the affordances and scientific concepts imparted within the scenarios (Figure 1).

Within a day following interaction, students completed a system usability evaluation based on the Computer System Usability Questionnaire (Lewis 1995) and Interactive Heuristic Evaluation Toolkit (Sussex University 2001). Twenty-seven usability constructs were evaluated on a 7-point Likert scale, where "disagree" was assigned a value of "1", and "agree", a value of "7." Additionally, three open-answer items were included to illuminate positive and negative aspects of using the system.

\subsubsection{Data Analysis}

Pre-/post-questionnaire responses were analysed for possible influences of interaction with NanoSim on nano attitudes. The attitude data were assigned values corresponding to the distance of the placed "X" along the corresponding VAS of each item, ranging from 0 to 10. Together with responses to the open-ended items, changes from pre- to post-interaction indicated the possible influence of interacting with NanoSim on students' attitude.

A qualitative analysis of the video data used Transana software (Woods and Fassnacht 2013) to perform a verbatim transcription and coding of student utterances and interactions with the system. Iterative viewings of the video data allowed for discoveries of critical events (Powell et al. 2003). Critical events emerged upon the analyser attempting to answer the question, "what is happening in this instance, in terms of science content, discovery, and interaction?" Evidence of a critical event was defined as an episode of student verbalization and/or interaction with the system that demonstrated at least one of the following observations:

- Interactive behaviours that seemed to influence reasoning and understanding.

- Student understanding of science concepts intended to be communicated by NanoSim.

- Inconsistencies between interaction and revealed student understanding.

- Student understanding of the simulation as a model of aspects of reality.

- Revealed attitudes, or changes thereof, towards the risks and benefits of nano.

- Utterances related to the usability of the system. 
Time-stamped intervals of video data encompassing critical events that emerged from the data were grouped into related categories and considered from both individual and group perspectives (Vallance and Martin 2012).

The usability survey (see constructs in Table 3 ) was analysed by calculating the mean and mode values of student responses to the Likert-scale items. Reversed wording construct values were recoded to the opposite number of the scale. Mean values greater than or equal to " 4 " were considered positive. Positive and negative factors of the simulation experience as well as specific links to usability aspects were also sought in the analysis.

\subsection{Results and Discussion}

Findings of the case study are presented and discussed by revisiting each of the three posed research questions.

\subsubsection{What cognitive and learning dimensions are afforded by students' interaction with the environment?}

Emergent themes pertaining to cognitive or learning processes included elements of offloading, experiential learning, embodied cognition, and motivation. The themes are presented together with critical event exemplars of student interactions with NanoSim.

\section{Interaction facilitates cognitive off-loading of mental processes onto the environment}

Analysis of students' interactions with NanoSim revealed facets of cognitive off-loading. Offloading reduces cognitive processing load through processes such as re-representation (Scaife and Rogers 1996). For example, rather than internally representing and processing new contexts, students allowed the system to re-represent the situation as an aid to their interpretation. One salient observation was that students who used the simulation to support cognition also engaged in pronounced gesturing. For example, Charlie ${ }^{1}$ referenced his observations and gestured towards the screen frequently while expressing his understanding (Figure 2). In this exemplar, he refers to observed emergent processes of the digital environment's representations of nanotube aggregation. While doing so, illustrates his understanding that the nanotubes spontaneously align, as shown by the following excerpt:

"I noticed when I brought them together, and left them there like in a constant motion ((student places hands overlapping and wiggles them back and forth) $)^{2}$ they kind of stick together. For example, ((points to screen bundle)). This one right here ((brings a single nanotube to the bundle almost in alignment)). See? And then they kind of attract each other. I don't know what kind of forces could be doing this but... It's something that brings these nanotubes together. " [Charlie, Video1, 5.51-6.19].

"It ((a nanotube)) is permanently in that place, but that is unless I pull it. And then I will be able to move it. If I let it be I think it still has some sort of force that might push it away, but after it gets back to its resting stage, it stays there. ((points to screen)) See?" [Charlie, Video1, 10.49-11.05]

Please insert Figure 2 about here

\footnotetext{
${ }^{1}$ Pseudonyms assigned.

${ }^{2}$ Text in italics indicates student uttered speech and bold italic text signifies speech or actions in focus in the analysis. Transcription notation key: $I$ : - interviewer speech, $((\ldots))$ - contextual information such as actions and gestures, = - continuation of an utterance without pause, ... - short pause, and [ ] - overlapping speech.
} 
FIGURE 2 Screenshots generated from the interactive think-aloud session conducted with Charlie illustrating the role of the virtual environment in offloading mental effort onto the environment.

Charlie's insistence that the researcher also observe the nanotubes on the screen, such as utterances such as "See?", and accompanying gestures towards the screen emphasized the simulation's importance for his developing understanding while using the external environment to re-present his reasoning and interpretation.

\section{Interaction facilitates experiential learning via experimentation and exploration}

Interaction with NanoSim afforded experiential learning of nano through experimentation (Dalgarno and Lee 2010, Kiili 2005). Evidence for students' experimentation were expressed hypotheses or an intent to discover the outcome of a specific action or observation. A critical event from Alex exemplifies the notion of experimental learning (cf. Figure 3), as indicated in the following interaction:

"I'm gonna try to put these two ((nanotubes))...uh... diagonally against one another $(($ perpendicular $))$ and see if they still want to be drawn $=$ I'm gonna see if they ((points to screen)) If they want to ((places hands palms towards one another approx $25 \mathrm{~cm}$ apart, then rotates and brings palms closer, fingers to wrist; gesture is performed between utterances Figure 3A)) change ((repeats previous action Figure 3B)) position ((half gesture)) but instead it seems like uh-..((student changes viewing perspective, rotating head to see more from left side and behind)) the nanotube and yes it crawls down ((makes a downward movement with left hand, orientation mirroring nanotubes, verbalizes simultaneously Figure 3C)) the other and yes they ((brings hands closer together, rotates palms aligning finger tips towards wrists of other hand-prior to verbalization)) now they ((repeats action during verbalization)) interacted with one another and lined up ((brings hands closer together, rotates palms, aligning finger tips towards wrists, touches palms together for emphasis; during verbalization)) together. Even when I place them diagonal ((places hands perpendicular Figure 3D )) from one another ((perpendicular)) one of the tubes or both of the tubes move so they first got further down ((slowly moves hands from the perpendicular, Figure $3 E$, to edges of hands touching, sliding them down one another to wrists and fingertips aligned, Figure $3 F$; oriented similarly to the nanotubes on-screen; action slightly precedes verbalizations) and then lined up next to another ((points one finger to screen))." [Alex, Video1, 12.41-13.44].

Alex's statement of intent "I'm gonna try..." in order to test a hypothesis that nanotubes will "still want to be drawn" indicates an experimental use of NanoSim. He reaffirms his intent with "I'm gonna see if they...want to change position." Following his manipulation of the nanotubes, he observed the result, deduced "instead it seems like", continued to observe and then concluded, "Even when I place them diagonal from one another one of the tubes or both of the tubes move so they first got further down and then lined up next to one another." He has understood that the starting orientation of nanotubes relative to one another does not affect their eventual parallel alignment. The datum suggests that Alex perceived NanoSim's potential experimentation affordance, and then implemented an experiment to test, and interpret, nanotube interaction. 


\section{Interaction facilitates embodied experiences for accessing nano}

Data also suggested that students' interactions with NanoSim afforded body-based and pseudo-haptic ${ }^{3}$ experiences as a means to access nano. Processes grounded in bodily experiences were evident in students' use of gestures to echo predicted position or movement of nanotubes. Returning to Alex's critical event from the section above, focus is on the gestures generated whilst reasoning about the spontaneous bundling of nanotubes (Figure 3 ).

Please insert Figure 3 about here

FIGURE 3 Screenshots (A-F) from Alex's interactive session illustrating various aspects of his use of hand gestures in connection with interpreting events in the nanoworld.

Alex used his hands to represent nanotube movements and interactions in concert with verbal commentary. In this example (Figure 3), he began with his hands approximately $25 \mathrm{~cm}$ apart, brought them closer together and oriented his fingertips to wrist, palms facing, in front of his body (Figure 3A). Prior to his use of language as a representation, he explained his thoughts with this specific bodily action. Alex repeated this gesture (Figure 3B) indicating that this was the orientation for which he was testing. Using gestures, he re-represented observed behaviour of nanotubes. He then swept his left hand downward describing that a nanotube "crawls down" (Figure 3C). Orienting his hands at right angles (Figure 3D), Alex deduced that nanotubes originating in a perpendicular configuration spontaneously reorient themselves in lengthwise alignment. The progressive reorientation maximizing surface area contact is represented through a new hand gesture. In this gesture, his left little finger's edge was placed on top of his right hand's thumb edge, palms facing opposite directions. The gesture began as before (Figure 3D) followed by a sliding down and rotating the palms (Figure 3E) until palms and fingertips were evenly placed (Figure 3F). Once the virtual environment re-represented the nanotubes in alignment, Alex concluded the event through a modified gesture, palms pressed together. During the critical event, Alex expressed his thinking and understanding about nanotubes' spontaneous alignment and bundling both verbally and through accompanying hand gestures that mirrored nanotube orientation and movement.

Data also demonstrated that the virtual nanoworld provided perceived sensory input sans a haptic device and induced pseudo-haptic experiences. Here, students often experienced nanotubes as tangible objects as evidenced by uttered vocabulary associated with weight and force. For example, Karin's interactions were associated with differentiating between various force strengths, without actual haptic perception of force. In the critical event below, she qualifies bonds between carbon atoms as "really strong" compared to those between nanotubes as "not that strong", while pulling on the virtual nanotubes using the gesture:

"The forces holding the carbon atoms together I think are covalent bonds. and uh.. uh... this is really strong and but uh the structure or the force keeping them um.. keeping the tubes close together is not that strong. I would guess.

I: How do you know that? Because I can pull them apart. And I can't pull the... I can't break the

\footnotetext{
${ }^{3}$ Pseudo-haptic feedback refers to the process of simulating haptic perception via visual feedback and user sensory-motor actions (Lécuyer, 2009).
} 
tube." [Karin, Video2, 8:20-9.01].

Students often perceived a haptic affordance of the virtual nanoworld that was not present, a potentially meaningful illusion provided through pseudo-haptic feedback (Lécuyer 2009).

\section{Interaction facilitates motivation for learning}

Analysis also suggested that NanoSim motivated some students' to learn about science phenomena. This motivation dimension was identified through students' spontaneously extended interactions and discussions of science concepts beyond the inquiries of the researcher. Their engagement with the science content indicated a seriousness toward solving the tasks and a peaked curiosity. Some students exhibited different learning characteristics compared to those observed during traditional classroom teaching, One case in point was Dennis, who in the traditional classroom setting exhibited an extremely shy personality, often soft-spoken, and rarely answering questions in whole-class and individual settings. However, during his interactive session with NanoSim, Dennis spoke confidently, often commenting on his intentions, observations and drawing real-time deductions as exemplified in the following critical event:

"I'm trying to put some ((nanotubes)) against this wall. But as soon as one end is loose they're gonna lose their gripping from the cell wall. And the other ones ((nanotubes)) sweep it away. [I:OK.] So I think this attraction between the cell wall and the tubes are not, it's not that strong. Which was visible between these tubes also. They are attracted to each other, but it's really easy to break them." [Dennis, Video2, 5.13-6.01].

Dennis described his intent with his interaction, what he was "trying to" achieve. He verbalized his observations that if "one end is loose" the nanotube would lose its "gripping" on the wall and that other nanotubes were able to dislodge an attached nanotube. These observations lead him to conclude that the "attraction between cell wall and the tubes are ...not that strong." Dennis then found another instance to support his conclusion. During these 48 seconds, Dennis spoke coherently and confidently about a science phenomenon, culminating with a scientific generalization. Since these qualities were not observed in the traditional classroom, the virtual environment might have played a motivational role.

Contrarily, Peter was a confident student in the classroom, speaking voluntarily and often dominating speaking time in lessons. During his interactive experience, Peter often mumbled and spoke softly. The interviewer had to encourage him to speak louder or repeat inaudible speech. Peter comments on his uncertainty as per the following:

"Yes, I can't draw conclusions. Really, I don't...I have no idea. I mean it's only carbon so there should be no polarity here which is usually a reason for movement I guess. In molecules and stuff..." [Peter, Video1, 16.42-16.56].

Peter stated that he "can't draw conclusions." He offered no explanation of what he observed despite being a student who performed well on traditional assessment and should have had an understanding of the concepts portrayed in the simulation. There was some internal conflict of understanding occurring in this critical event. Peter attributed polarity as a driving force of motion. His prior understanding of polarity rested upon a requirement of two different species for a charge difference, which is in conflict with his observation of interacting structures containing atoms of only one element.

These exemplars illustrate the virtual nanoworld's affordance of motivation for learning. Dennis was strongly motivated to interact with the environment and discuss the science content. Despite his keen interaction, Peter was however insecure in connecting what 
was "learned" in the traditional classroom with what was being "learned" with the environment. Students can actively explore a virtual environment and yet remain disengaged from learning tasks or have a reduced quality of learning. Results suggest that although NanoSim was a motivating environment for learning science, further study in which students work on specific learning tasks with and without teacher guidance is needed to discern the degree of afforded engagement (Lim et al. 2006).

\subsubsection{To what extent are students' attitudes towards the potential benefits and risks of nanotechnology influenced by interaction with the virtual environment?}

Student responses varied from pre- to post-interaction with three constructs triggering the greatest shifts in attitude for three or more students (Table 1).

TABLE 1 Results of pre- to post-attitudinal constructs after students' interaction with NanoSim. The scale corresponded to $0=$ Disagree to $10=$ Agree for the first two constructs and $0=$ Beneficial to $10=$ Risky for the third construct.

\begin{tabular}{lll}
\hline Attitudinal Construct & Mean Values (n=10) \\
\cline { 2 - 3 } & $\begin{array}{l}\text { Pre- } \\
\text { interaction }\end{array}$ & $\begin{array}{c}\text { Post- } \\
\text { interaction }\end{array}$ \\
$\begin{array}{l}\text { "Nanotechnology would not harm our health" } \\
\text { (from Lin et al. 2012) }\end{array}$ & 7.40 & 4.48 \\
$\begin{array}{l}\text { "The toxicity of nano-particles may be even higher than that of } \\
\text { microscopic particles like asbestos" } \\
\text { (from Lin et al. 2012; Siegrist et al. 2007) }\end{array}$ & 5.92 & 6.64 \\
$\begin{array}{l}\text { How beneficial or risky do you consider the industrial } \\
\text { manufacturing of nanotubes to be for Swedish society as a whole? } \\
\text { (from Siegrist et al. 2007) }\end{array}$ & 2.26 & 4.34 \\
\hline
\end{tabular}

The shift on the first two constructs (Table 1) indicates that the interactive experience resulted in some students re-evaluating their attitudes of risk or benefit towards nano. The shift in the third construct may have resulted from students' unfamiliarity with concrete nano applications prior to interaction; four students offered neither a specific nor a general example in the open question that probed associations with terms "nanoscience" and "nanotechnology." Dennis, Susan, and Maria wrote of waterproof and lightweight materials and sunscreen in their open responses prior to interaction. Post-interaction, five students responded positively towards medical applications of nano with three references to treating cancer through tumour destruction, which linked directly to the therapy scenario in the system.

"The interaction made it easier to understand nanotechnology since it gave a very clear picture of how cancer cells can be destroyed, thus my understanding of how nanotechnology works has increased. The interaction also showed the negative aspects but overall it gave me a positive attitude towards nanotechnology." [Lucy].

In her written response above, Lucy expressed a positive attitude, with reservation for risk, explicitly referencing the "nano-therapy" scenario. Results suggest that the experience succeeded in bringing about fact-based attitude, specifically in relation to cancer therapy. The 
construct for the industrial manufacturing of nanotubes elicited seven positive responses (post-interaction); two of these shifted from the "risky" to the "beneficial" pole.

To further explore the influence of the immersive environment on students' attitudes towards nano, participants were asked to reference specific aspects of the two scenarios that they associated with the terms "risk" and "benefit". Table 2 shows the frequency of responses within the emergent categories. For the concept "risk," five students wrote "bundling", "accumulation", or similar. Four students referred to "inhalation of nanotubes" or "clogging/toxicity" in the lungs as aspects of "risk." Seven students exemplified "benefit" with the functionalization of nanotubes. The cure or treatment of cancer featured in four students' concretizations of "benefit" whilst three specified steps in tumour cell destruction that were depicted in the "nano-therapy" scenario.

TABLE 2 Categories of student response frequencies linking their interactive experiences with NanoSim to the concepts of "risks" and "benefit"

\begin{tabular}{|c|c|c|c|}
\hline & Category & Example of response & Freq. \\
\hline \multirow{4}{*}{ Risk } & Bundling & $\begin{array}{l}\text { "Nanotubes bundle and are bonded together with strong } \\
\text { forces that are difficult to break." (Susan) }\end{array}$ & 5 \\
\hline & Respiratory difficulties & $\begin{array}{l}\text { "If the poisonous nanotubes are inhaled they might form } \\
\text { bundles that can damage lungs." (Dennis) }\end{array}$ & 4 \\
\hline & Interaction strength & "Hard for the body to break down." (Lucy) & 4 \\
\hline & Intermolecular forces & $\begin{array}{l}\text { "The bundling due to Van der Waal forces might pose a } \\
\text { risk..." (Alexander ) }\end{array}$ & 2 \\
\hline \multirow{3}{*}{ Benefit } & $\begin{array}{l}\text { Nanotube modification/ } \\
\text { functionalization }\end{array}$ & $\begin{array}{l}\text { "Being able to program nanotubes to target specific } \\
\text { cells..." (Peter) }\end{array}$ & 7 \\
\hline & Cancer cure/treatment & "Could be a possible cure for cancer..." (Karin) & 4 \\
\hline & $\begin{array}{l}\text { Tumor cell destruction } \\
\text { process }\end{array}$ & $\begin{array}{l}\text { "They [nanotubes] attach to disease cells and when } \\
\text { exposed to infrared light they produce heat..." (Dennis) }\end{array}$ & 3 \\
\hline
\end{tabular}

In their written open responses, students generally expressed positive views towards nano. However, their VAS responses revealed conservative views dominated by risk associations. According to Lee et al. (2005), risks as well as potential benefits are perceived in a balanced manner during early stages of technological development, which serves as a possible explanation of the revealed duplicity in attitude. Quantitatively, the student attitude responses did not shift greatly from pre- to post-interaction. The qualitative responses post-interaction showed a richness in science concepts integrated into students' explanations of attitude that was not present prior to interaction with NanoSim.

\subsubsection{How usable is the interactive virtual environment from a student-user perspective?}

The findings revealed the NanoSim virtual learning environment received favourable usability scores overall. The usability survey categories, corresponding constructs, and mean values of student responses are presented in Table 3.

TABLE 3 Mean values from the usability survey results ( $n=10)$ showing four main usability 
categories in bold and underlying constructs. Negative constructs are in italics with scores reversed to correspond to positively formulated constructs. For all constructs $1=$ Disagree and $7=$ Agree.

Usability Categories with sample positive and negative constructs

Flexibility and Ease of Use

Overall, I am satisfied with how easy it was to use the simulator.

It was simple to use NanoSim.

Too much of the information was given in the written form.

I felt comfortable using NanoSim.

It was easy to learn to use NanoSim.

The language options were limited.

Information, Help and Documentation

The organization of information on the system screens was clear.

It was easy to find the information I needed.

The information provided in NanoSim was difficult to understand.

The instructional text was clear and understandable.

The information was effective in helping me complete the tasks and scenarios.

Whenever I made a mistake using NanoSim, I recovered easily and quickly.

It was difficult to find help within the simulation.

The system gave error messages that clearly told me how to fix problems.

\section{Consistency and Mapping}

The text sections contain familiar words, concepts and phrases.

The control words and functions were similar throughout the system.

The simulation was arranged in a natural or logical order.

I was unable to quickly understand how to move from one section to another.

I felt the simulation's various parts belonged together.

Navigation and Constraints

I could tell where I was in the simulation at all times.

I could not see what I had already explored.

There were aids in the simulation to help me quickly get to where I wanted.

I found the simulation responded directly to any changes I tried to enact.

I easily found the control buttons to maneuver in the simulation.
Mean Values 
The interactive gesture was difficult to form.

I remembered how to use the gesture from one interactive scenario to another.

The simulation was easy to control with the gesture.

The usability results indicate that students were comfortable using and controlling the system. Constructs within the category, "Flexibility and Ease of Use," were positively evaluated by most students, and received a mean score of 4.9. Eight students felt comfortable working within the environment and found it easy to learn. Students scored the "Information, Help, and Documentation" within the system a mean value of 5.5. The informative language was familiar to the users, and the information was evaluated as being clearly organised. The category "Consistency and Mapping" scored a mean of 5.6. Students were familiar with the vocabulary employed in NanoSim and the system seemed to convey a consistent and intuitive system design, as shown by the following response:

"The screen content was easily recognizable and the objectives was [were] clear."

The "Navigation and Constraints" category scored a mean value of 4.9. Users were enthused by the ability to control NanoSim without an action-mediating device, with one student suggesting a "New way to interact with the system, without any controls or mouse." Overall, students expressed satisfaction with the system design regarding organization and navigation.

The usability study also revealed aspects of the system design that require future improvement. Concerning flexibility and ease of use, students who scored the environment low on the constructs "Overall, I am satisfied with how easy it was to use the simulator", and "It was simple to use NanoSim.", also delivered low scores for constructs concerning control of the system with the gesture and navigating within the system. The in-development help function expectedly scored low, as evident in the scores of 3.8 for construct, "It was difficult to find help within the simulation", and 2.2 for "The system gave error messages that clearly told me how to fix problems". Some students experienced difficulties in forming the controlling gesture (Figure 1) as evident from the 3.8 score for the construct "The interactive gesture was difficult to form", and open responses such as, "Nanotubes did not always react to the gesture". The construct "The simulation was easy to control with the gesture" scored higher at 4.2, indicating that once the gesture was formed, controlling the system only posed problems for some users whilst others experienced few impediments.

Future work could aim at what aspects of usability can provide a measure of the virtual environment's utility for educational goals (Stanney et al. 2003).

\section{An Interactive Nanoworld for Communicating Nano-Knowledge in the Classroom}

Given the educational case study described above, this chapter section provides readers with access to a personal computer (PC)-based version (NanoSim-PC) of the described virtual nanoworld (Figure 1, see section 4.3 for information about installation). We also offer guidance in how the content and interactive features of NanoSim-PC could be used as an educational tool to expose learners to core nano-concepts and principles in the classroom.

\subsection{NanoSim-PC program structure}

Upon starting the program, users are presented with a selection of four scenarios, each of which provides access to a visualized nanoworld in a unique configuration of context, content and visual features (Table 4). The dynamic visualization in Scenarios $1 \mathrm{a}$ and $1 \mathrm{~b}$ are based on a simulation model of the interaction between nanotubes, while the model 
underlying Scenarios $2 \mathrm{a}$ and $2 \mathrm{~b}$ simulates interactions between modified nanotubes and receptor molecules on cell surfaces. Scenarios $1 \mathrm{~b}$ and $2 \mathrm{~b}$ represent more advanced visualizations of the same underlying models and include additional visual information and objects. Scenarios 1a and 2a correspond to those in the immersive NanoSim implementation described in the case study above (section 3). Each scenario consists of a sequence of displays that comprises: i) background information about the scenario, ii) the dynamic nanoworld visualization, and iii) follow-up information and traversal through levels of scale from the nanoscopic level to the macroscopic level.

TABLE 4 Conceptual content and features of the four interactive scenarios in NanoSim-PC

\section{Interactive scenarios}

$\begin{array}{lll}\begin{array}{l}\text { Conceptual } \\ \text { content }\end{array} & \begin{array}{l}\text { Properties of carbon nanotubes and } \\ \text { the basis of nanotube aggregation }\end{array} & \begin{array}{l}\text { Reversible binding, equilibrium and the } \\ \text { basis for site-specific accumulation } \\ \text { ("targeted drug delivery") }\end{array}\end{array}$

$\begin{array}{ll}\begin{array}{l}\text { Simulation } \\ \text { model }\end{array} & \begin{array}{l}\text { Simulation of the interaction between } \\ \text { carbon nanotubes }\end{array}\end{array}$

\section{Basic nano} scenario

\section{Advanced nano scenario}

\section{Scenario 1b}

Emphasises the energy dynamics

Scenario 1a
Nanotubes in solution move
randomly through Brownian motion.
If nanotubes happen to be in close
proximity, they will attract each other
so that they move closer. The
nanotubes on the screen will tend to
self-assemble and form one or more
"bundles".
[Insert
Figure_Table_4_upper_left_corner.pn
g about here]
underlying Scenario 1a. When a user "grabs" a nanotube within interaction distance from another, an energy diagram is simultaneously displayed to indicate the current intermolecular potential value on a graph of the distance-dependence of the potential.

[Insert

Figure_Table_4_bottom_left_corner. png about here]
Simulation of the interaction between modified carbon nanotubes and cell surface receptors

\section{Scenario 2a}

Nanotubes are modified by attaching molecules that bind to receptors on tumor cells in the body. The modified nanotubes flow past a cancer cell surface that expresses tumor-specific antigens. As the modified structures on the nanotubes approach within interaction distance they "stick" temporarily.

[Insert

Figure_Table_4_upper_right_corner.png about here]

\section{Scenario 2b}

Emphasises the localised accumulation in the targeted drug delivery in scenario $2 \mathrm{a}$. Displays two cell surfaces: a cancer cell and a healthy cell with no expressed antigen. The scenario displays the percentage of cell surface antigens that are bound, allowing the user to directly observe properties of binding equilibria.

[Insert

Figure_Table_4_bottom_right_corner.pn $\mathrm{g}$ about here]

Learners can engage with each scenario by manipulating the content of the simulation. They do this by placing the mouse pointer above the selected nanotube and pressing and holding the mouse button while moving the mouse pointer. The interface between the user and the virtual system is represented graphically by an elastic "rubber band" which 
"stretches" when the user applies a force to the nanotube by "pulling" it in a direction. An anaglyph stereo functionality allows users to simultaneously view the nanoworld in 3D using red-cyan glasses. Apart from moving the nanotubes with the mouse, learners can click on various information icons distributed in each of the four nano-scenarios.

\subsection{Nano education interventions with NanoSim-PC}

The interactive experience with NanoSim-PC can be adapted to a variety of nano education contexts and purposes. Purposefully designed non-directed user interaction with the system contributes to this flexibility. The literature indicates that some guidance is nevertheless important for promoting learning with simulations, although such scaffolding can be delivered outside of the system (e.g. McElhaney et al. 2015). In the following, three possible learning activities are outlined to provide teachers with ideas for how NanoSim-PC could be integrated in their teaching. We encourage teachers to further develop these teaching design sketches, and/or construct their own teaching sequences.

\subsubsection{NanoSim-PC in teaching about simulations and models}

The role of models in science and technology is an important part of upper secondary science curricula across the world. Literature suggests that simulations may be a powerful tool for developing a model-based understanding of science (Develaki 2017). In a nano education context, NanoSim-PC can be used as a focus representation for discussions about models in science and teaching: What are the limitations and strengths of the simulation? What is the simulation intended to model, and at what level of scientific accuracy? What trade-offs needed to be made in order to model the represented objects and processes in the simulation? Potential learning activities could include teacher-led class discussion about models in science, possibly in conjunction with modelling activities using other simulation software (see section 2.2). Teachers can find further information behind the development of the NanoSim framework in Lundin Palmerius et al. (2012). The model specification was aimed at providing a coarse-grained and computationally simple simulation, so that real-time rendering and interactive manipulation of the modelled system would be possible. Briefly, the simulation models nanotubes as interlinked hard cylinders with rounded ends. Each cylinder subsection of a nanotube is rigid while the links between cylinders allow for some flexibility. A physics engine detects collisions between the hard cylinders of adjacent nanotubes. The intermolecular attractive and repulsive interactions between carbon nanotubes are approximated by a Lennard-Jones potential that extends outside of the hard cylinder shell. Intermolecular interaction between the surface of modified carbon nanotubes and cell receptors are modelled as simple charge-charge interactions. Brownian motion is simulated by applying stochastic forces to the nanotubes.

\subsubsection{NanoSim-PC in teaching about nanoscience and technology}

NanoSim was designed to integrate twenty core concepts that our research has shown to be fundamental to understanding nano (Schönborn et al. 2015). Within NanoSim-PC, these concepts are included as concise conceptual statements and accompanying visuals that can be accessed through information icons (represented as purple disks embedded in the nanoscenarios). Examples of integrated conceptual statements include, "A nanometer is 1000000 000 ( 1 billion) times smaller than a meter", "The strength of the forces between objects at the nanoscale play a more dominant role than gravity", "Nanotubes can be designed to bind to specific target cells inside the body", and "The properties of objects at the nanoscale may give rise to both advantages and risks of nanotechnology". Therefore, NanoSim-PC can be used as an environment for individual and collaborative problem-solving activities. 
Potential learning activities could be constructing molecular mechanistic explanations for nanoscientific phenomena such as nanotube aggregation in solution and targeted drug delivery. Such explanations would require students to consider the complex interactions of different factors such as relative force magnitudes, exposed surface area in relation to volume, collisions and interactions between molecules (including solvent molecules), interaction specificity, and binding equilibria. In doing so, students would be required to integrate concepts by making links to, and across, different traditional school subjects (physics, chemistry and biology) while challenging intuitive beliefs about molecular phenomena (e.g. that molecules "seek out" their target binding site).

\subsubsection{NanoSim-PC in teaching about nanotechnology as a socioscientific issue}

Nanotechnology is surrounded by hopes and fears about the effects on society and the natural environment. The intertwinement of nanotechnology development with sometimesconflicting values and interests among different stakeholders can make it a controversial science. Navigating such issues requires nanoscientific knowledge as well as the ability to assess ethical concerns and weigh the potential risks and benefits of technology development (Jones et al. 2013). In this regard, NanoSim-PC could function as a representation of the nanoscience that underlies potential risks and benefits of a specific nanotechnological innovation (i.e. carbon nanotubes).

Potential learning activities could include debates or discussions regarding risks and benefits of carbon nanotubes to different stakeholders. Herein, NanoSim-PC could be used as part of preparatory material, together with news articles and communications from different interest groups. Another possibility is for students to prepare popular scientific presentations of research papers from the primary literature, using NanoSim-PC as a communicative tool. The task could be made more authentic by including a peer teaching format, wherein older students are tasked with explaining to younger pupils what nanotechnology is and why it can be interpreted as controversial.

\subsection{System requirements and access to the NanoSim-PC program}

The NanoSim-PC software is available for download at http://urn.kb.se/resolve?urn=urn:nbn:se:liu:diva-163527. The source code is licensed under GNU GPL, which means that anyone can use it freely and modify the source code, and even redistribute their new application, provided they distribute their own source code together with the executable. However, the media used by the software are not distributed under GNU GPL, but rather as a combination of public domain, Creative Commons and retained rights the respective licenses are listed in the repository.

At the time of writing, the installer is available in a version for the Microsoft Windows operating system, but can be compiled for OSX or Linux from source. In terms of hardware, most desktop and laptop computers should have the memory, storage, graphics and processor capacity for running the program. However, the program requires a graphics card and driver supporting OpenGL for it to run optimally. NanoSim-PC is implemented with H3D API, which is a cross platform scenegraph library that is programmed by a combination of languages. The nano particle simulation and interaction principles are implemented in $\mathrm{C}++$. The scenes are defined in X3D and the user interface is implemented in Python. Static graphics and texts are drawn in SVG and converted to PNG for use in the application.

\section{Conclusions and Implications}

This chapter has explored the role of interactive visualization in nano education and how virtual nanoworlds can be used for learning and teaching. The literature suggests that sensory perceptual interactions can offer an intuitive basis for building knowledge about 
abstract nano-concepts. In addition, interaction with these environments has also been linked to an improved ability to transfer nano-related knowledge to new contexts. Furthermore, students' experiences with multisensory visualization platforms has also been related to increased interest and engagement with nanoscientific content.

The results from the reported case study of upper-secondary students' interactions with the gesture-based NanoSim environment revealed multiple cognitive affordances and dimensions of system usability. Results indicate that immersion and gestural interaction within the virtual nanoworld could serve as a pathway for engendering nano-related understanding. The findings also highlight the potential of embodied experiences in accessing otherwise unobservable nanoscale ideas by mapping sensorimotor interactions in the world onto virtual nano-object interactions. Interaction with the virtual environment may also act as an agent of change with respect to attitudes toward perceived benefits and risks of nano.

In accessing the personal computer program NanoSim-PC, teachers can bring the nanoworld into the classroom. The interactive environment can be used to design various educational interventions around representational, conceptual and socioscientific aspects of nano. Herein, various core nano-concepts can be linked to otherwise traditional secondary school physics, chemistry and biology concepts and simultaneously transcend several scientific disciplines in keeping with the convergent nature of nano. At the same time, constructing such knowledge provides students with the opportunity to make informed, scientifically-based decisions about perceived dangers and advantages of nanotechnology.

Although research has revealed various positive aspects, several challenges are associated with integrating visualization environments into nano education. These include the danger of trivializing or oversimplifying extremely complex nanoscale mechanisms, and the need to reach a suitable compromise between technological and conceptual constraints in designing meaningful visualization environments. To exploit the pedagogical opportunities that virtual environments can bring to nano education, future educational research should focus on larger numbers of participants, further formal and informal sites of investigation, and on the interplay between virtual environment design and intended learning opportunities.

\section{Acknowledgements}

This work was supported by the Swedish Research Council (Vetenskapsrådet, grant 20115569). The authors thank the students that participated in the case study and colleagues at Linköping University for valuable discussions.

\section{References}

Amin, T.G., Jeppsson, F., Haglund, J. 2015. Conceptual metaphor and embodied cognition in science learning: Introduction to special issue. Int. J. Sci. Educ. 37: 745-758.

Bainbridge, W.S. 2002. Public attitudes toward nanotechnology. J. Nanopart. Res. 4: 561570.

Blonder, R. and Sakhnini, S. 2012. Teaching two basic nanotechnology concepts in secondary school by using a variety of teaching methods. Chem. Educ. Res. Prac. 13: 500-516.

Bower, M. 2008. Affordance analysis-matching learning tasks with learning technologies. Educ. Media Int. 45: 3-15.

Bowman, D.A., Gabbard, J.L., Hix, D. 2002. A survey of usability evaluation in virtual environments: classification and comparison of methods. Presence-Teleop. Virt. 11: 404424.

Cobb, M.D. and Macoubrie, J. 2004. Public perceptions about nanotechnology: Risks, benefits and trust. J. Nanopart. Res. 4: 395-405.

Dalgarno, B. and Lee, M.J. 2010. What are the learning affordances of 3-D virtual environments?. Br. J. Educ. Technol. 41: 10-32. 
Derry, S.J., Pea, R.D., Barron, B. et al. 2010. Conducting video research in the learning sciences: Guidance on selection, analysis, technology, and ethics. J. Learn. Sci. 19: 3-53.

Develaki, M. 2017. Using computer simulations for promoting model-based reasoning. Sci. \& Educ. 26: 1001-1027.

Dyehouse, M.A., Diefes-Dux, H.A., Bennett, D.E., Imbrie, P.K. 2008. Development of an instrument to measure undergraduates' nanotechnology awareness, exposure, motivation, and knowledge. J. Sci. Educ. Technol. 17: 500-510.

Fazio, R.H. and Zanna, M.P. 1981. Direct Experience And Attitude-Behavior Consistency. In Advances in experimental social psychology (14: 161-202). Academic Press.

Gardner, G., Jones, G., Taylor, A., Forrester, J., Robertson, L. 2010. Students' risk perceptions of nanotechnology applications: implications for science education. Int. J. Sci. Educ. 32:1951-1969.

Gillet, A., Sanner, M., Stoffler, D., Olson, A. 2005. Tangible interfaces for structural molecular biology. Structure 13: 483-491.

Goodsell, D.S. 2006. Seeing the nanoscale. Nano Today 1: 44-49.

Hartson, R. 2003. Cognitive, physical, sensory, and functional affordances in interaction design. Behav. Inform. Technol. 22: 315-338.

Healy, N. 2009. Why Nano Education?. J. Nano Educ. 1: 6-7.

Hendrick, T.A., Fischer, A.R., Tobi, H., Frewer, L.J. 2013. Self-reported attitude scales: current practice in adequate assessment of reliability, validity, and dimensionality. J. Appl. Soc. Psychol. 43: 1538-1552.

Höst, G.E., Schönborn, K.J., Lundin Palmerius, K.E. 2013. A case-based study of students' visuohaptic experiences of electric fields around molecules: Shaping the development of virtual nanoscience learning environments. Educ. Res. Internat. 2013: Article ID 194363, 11 pages, doi:10.1155/2013/194363.

Jones, M.G., Andre, T., Superfine, R., Taylor, R. 2003. Learning at the nanoscale: The impact of students' use of remote microscopy on concepts of viruses, scale, and microscopy. J. Res. Sci. Teach. 40: 303-322.

Jones, M. G., Blonder, R., Gardner, G. E., Albe, V., Falvo, M., Chevrier, J. 2013. Nanotechnology and nanoscale science: Educational challenges. Int. J. Sci. Educ. 35: 14901512 .

Kiili, K. 2005. Digital game-based learning: Towards an experiential gaming model. Internet High. Educ. 8: 13-24.

Kozma, R., Chin, E., Russell, J., Marx, N. 2000. The roles of representations and tools in the chemistry laboratory and their implications for chemistry learning. J. Learn. Sci. 9: 105-143.

Laherto, A. 2010. An analysis of the educational significance of nanoscience and nanotechnology in scientific and technological literacy. Sci. Educ. Int. 21: 160-175.

Lécuyer, A. 2009. Simulating haptic feedback using vision: A survey of research and applications of pseudo-haptic feedback. Presence-Teleop. Virt. 18: 39-53.

Lee, C.J., Scheufele, D.A., Lewenstein, B.V. 2005. Public attitudes toward emerging technologies: Examining the interactive effects of cognitions and affect on public attitudes toward nanotechnology. Sci. Commun. 27: 240-267.

Lewis, J. R. 1995. IBM Computer Usability Satisfaction Questionnaires: Psychometric Evaluation and Instructions for Use. Int. J. Human-Comp. Interac. 7: 57-78.

Lim, C.P., Nonis, D., Hedberg, J. 2006. Gaming in a 3D multiuser virtual environment: Engaging students in science lessons. Br. J. Educ. Technol. 37: 211-231.

Lin, S.F., Lin, H.S., Wu, Y.Y. 2013. Validation and exploration of instruments for assessing public knowledge of and attitudes toward nanotechnology. J. Sci. Educ. Technol. 22: 548559. 
Liu, Z. and Stasko, J. 2010. Mental models, visual reasoning and interaction in information visualization: A top-down perspective. IEEE Trans. Vis. Comput. Graph. 16: 999-1008.

Lundin Palmerius, K.E., Höst, G.E., Schönborn, K.J. 2012. An interactive and multi-sensory learning environment for nano education. In Haptic and Audio Interaction Design, eds. C. Magnusson, D. Szymczak, and S. Brewster, 81-90. Berlin: Springer.

McElhaney, K.W., Chang, H.Y., Chiu, J. L., Linn, M.C. 2015. Evidence for effective uses of dynamic visualisations in science curriculum materials. Stud. Sci. Educ. 51: 49-85.

McNemar, Q. 1946. Opinion-attitude methodology. Psychol. Bull. 43: 289.

McWhorter, R. and Lindhjem, K. 2013. Virtual learning environments: How they can benefit nanotechnology safety education. IEEE Nanotechnol. Mag. 7: 15-17.

Murcia, K. 2013. Secondary school students' attitudes to nanotechnology: What are the implications for science curriculum development? Teach. Sci. 59: 15.

Myers, N. 2008. Molecular embodiments and the body-work of modeling in protein crystallography. Soc. Stud. Sci. 38: 163-199.

Norman, D.A. 1999. Affordance, conventions, and design. Interactions 6: 38-43.

PhET Interactive Simulations, University of Colorado Boulder, http://phet.colorado.edu/. Accessed 24 April 2018.

Powell, A.B., Francisco, J.M., Maher, C.A. 2003. An analytical model for studying the development of learners' mathematical ideas and reasoning using videotape data. J. Math. Behav. 22: 405-435.

Scaife, M. and Rogers, Y. 1996. External cognition: how do graphical representations work?. Int. J. Hum-Comput. St. 45: 185-213.

Schönborn, K.J., Höst, G.E., Lundin Palmerius, K.E. 2016a. Nano education with interactive visualization. Nano Today 11: 543-546.

Schönborn, K. J., Höst, G. E., Lundin Palmerius, K. E. 2016b. Interactive visualization for learning and teaching nanoscience and nanotechnology. In: K. Winkelmann, B. Bhushan (Eds.), Global Perspectives of Nanoscience and Engineering Education (pp. 195-222). Basel: Springer.

Schönborn, K.J., Höst, G.E., Palmerius, K.L. 2015. Measuring understanding of nanoscience and nanotechnology: Development and validation of the nano-knowledge instrument (NanoKI). Chem. Educ. Res. Pract. 16: 346-54.

Schönborn, K. J., Höst, G. E., Palmerius, K. L., Flint, J. 2014. Development of an interactive immersion environment for engendering understanding about nanotechnology: Concept, construction, and implementation. Int. J. Virt. Pers. Learn. Environ. 5: 40-56.

Siegrist, M., Keller, C., Kastenholz, H., Frey, S., Wiek, A. 2007. Laypeople's and experts' perception of nanotechnology hazards. Risk Anal. 27: 59-69.

Stanney, K.M., Mollaghasemi, M., Reeves, L., Breaux, R., Graeber, D.A. 2003. Usability engineering of virtual environments (VEs): Identifying multiple criteria that drive effective VE system design. Int. J. Hum-Comput. St. 58: 447-481.

Stevens, S.Y., Sutherland, L.M. and Krajcik, J.S., 2009. The big ideas of nanoscale science and engineering. NSTA press.

Sussex University. 2001. Interactive Heuristic Evaluation Toolkit [online software]. Available from http://www.id-book.com/firstedition/catherb/index.htm

Vallance, M. and Martin, S.M., 2012. Assessment and learning in the virtual world: Tasks, taxonomies and teaching for real. J. Virtual Worlds Res. 5.

Wilson, M. 2002. Six views of embodied cognition. Psychon. B. Rev. 9: 625-636.

Winkelmann, K. 2016. Get the word out. Nat. Nanotechnol. 11: 396.

Woods, D. and Fassnacht, C. 2013. Transana v 2.53 [computer software]. Madison, WI.

Spurgeon Woods LLC. Available from https:// www.transana.com 
Xie, C., Tinker, R., Tinker, B., Pallant, A., Damelin, D., Berenfeld, B. 2011. Computational experiments for science education. Science 332: 1516-1517. 
Figure 1:

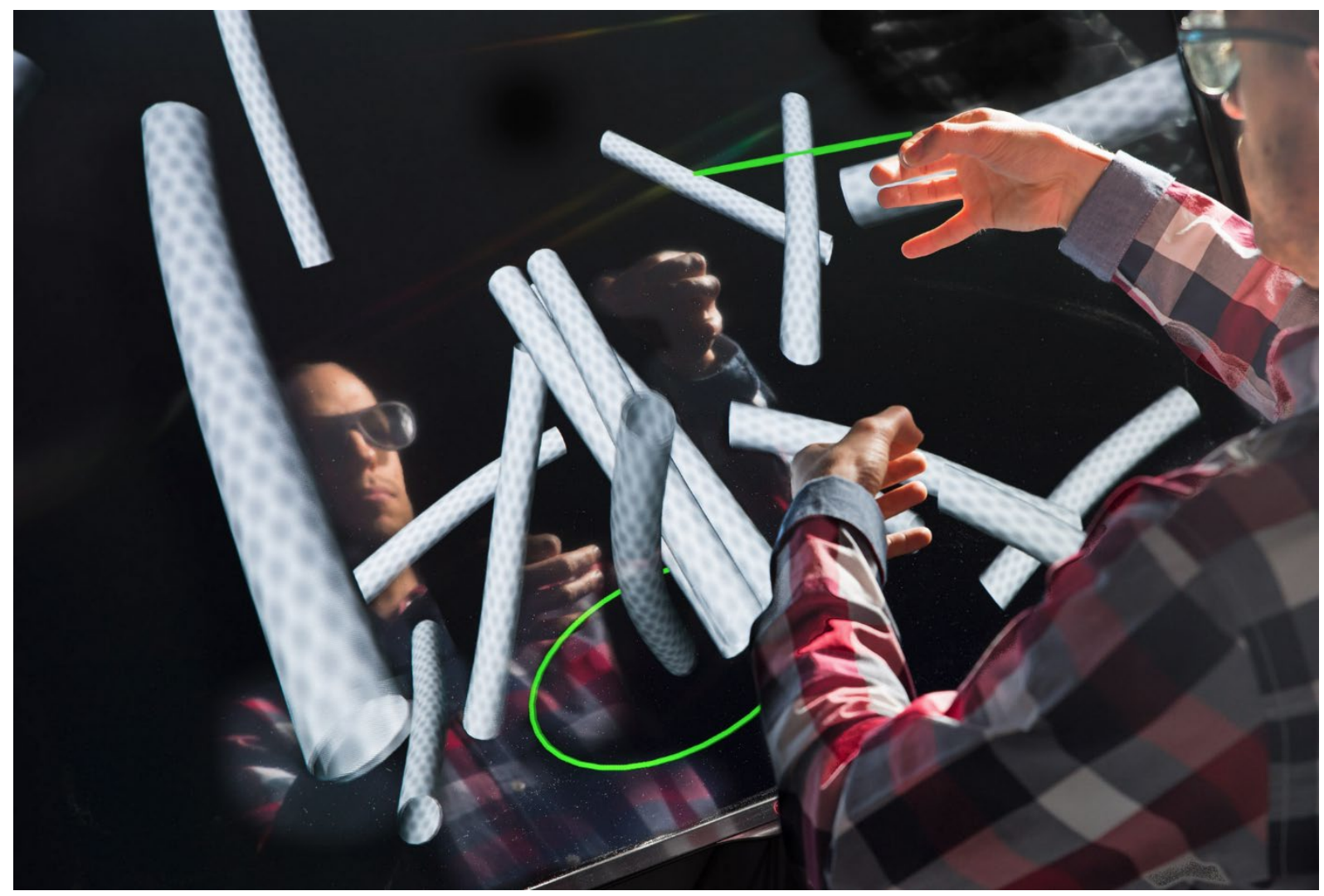


Figure 2:
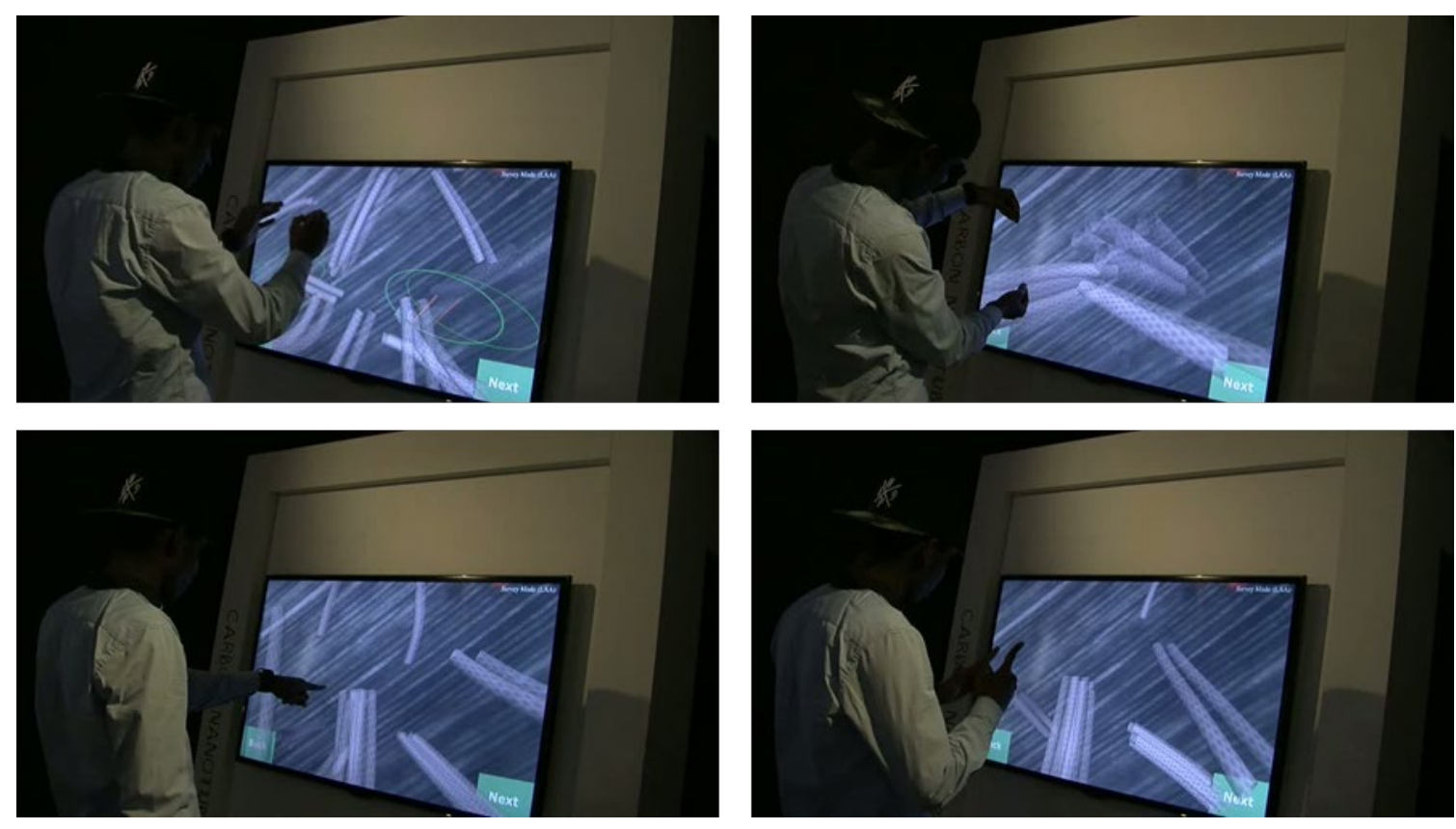
Figure 3:
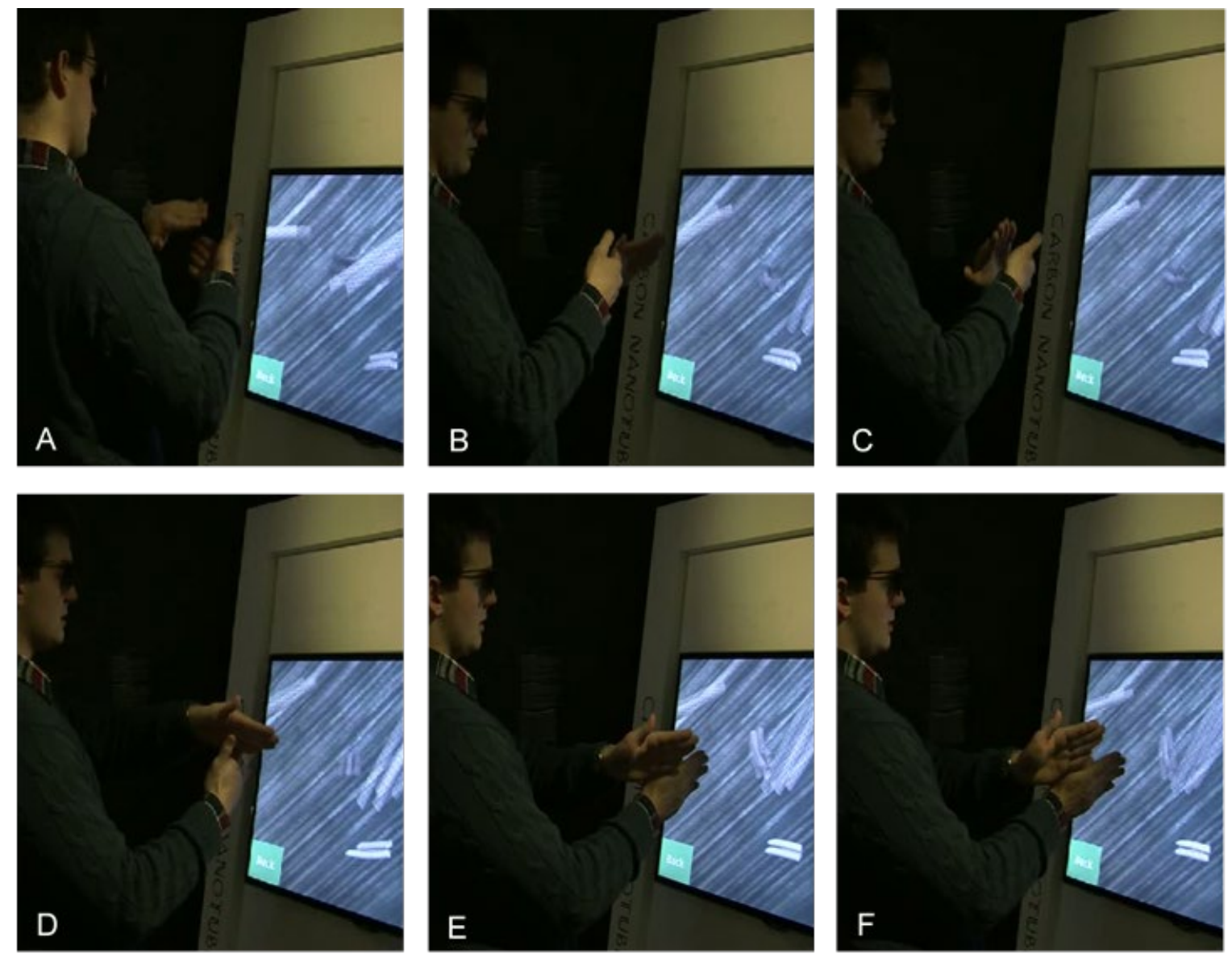
Figure in Table 4 (bottom left corner):

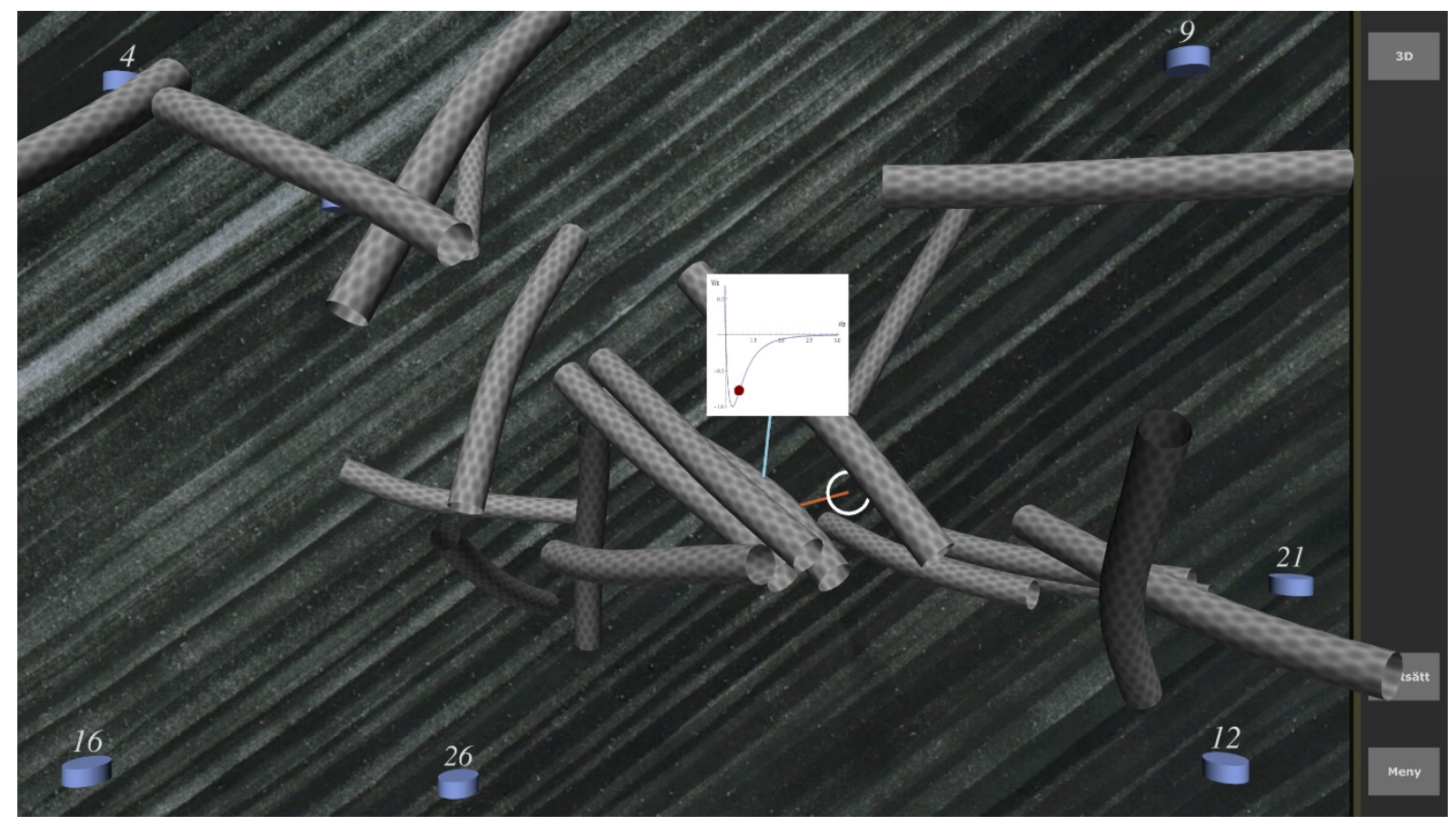


Figure in Table 4 (bottom right corner):

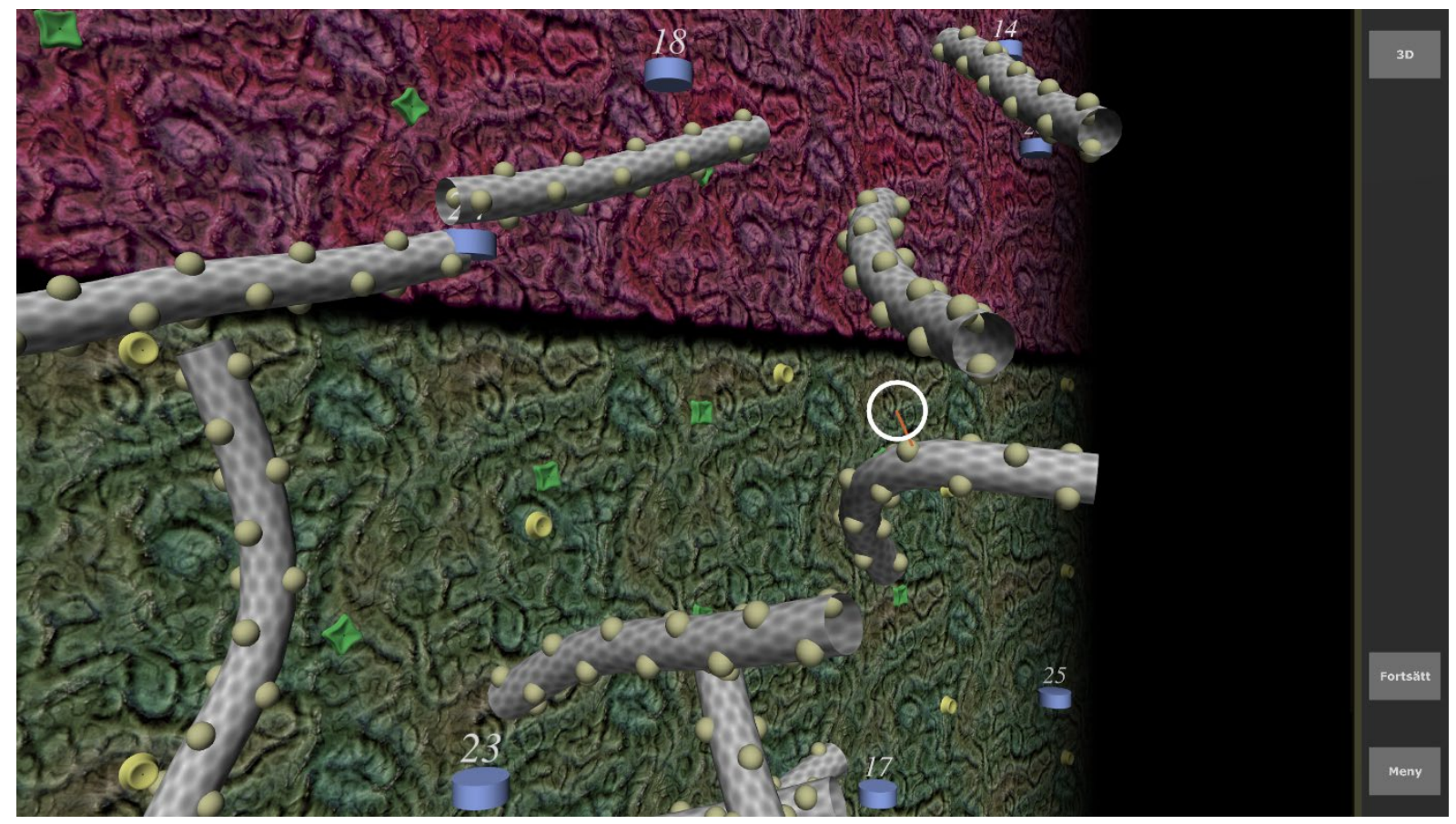


Figure in Table 4 (upper left corner):

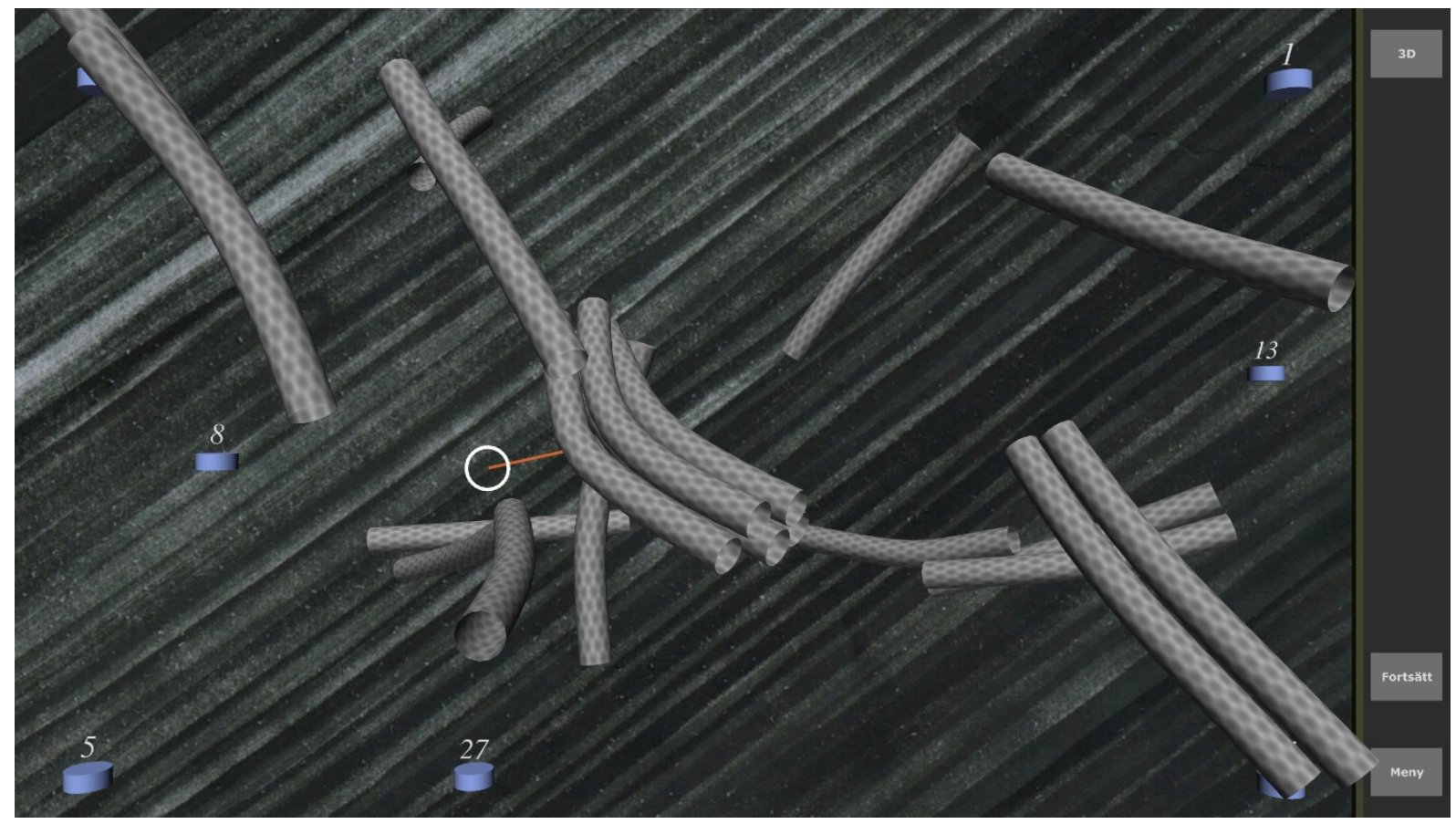


Figure in Table 4 (upper right corner):

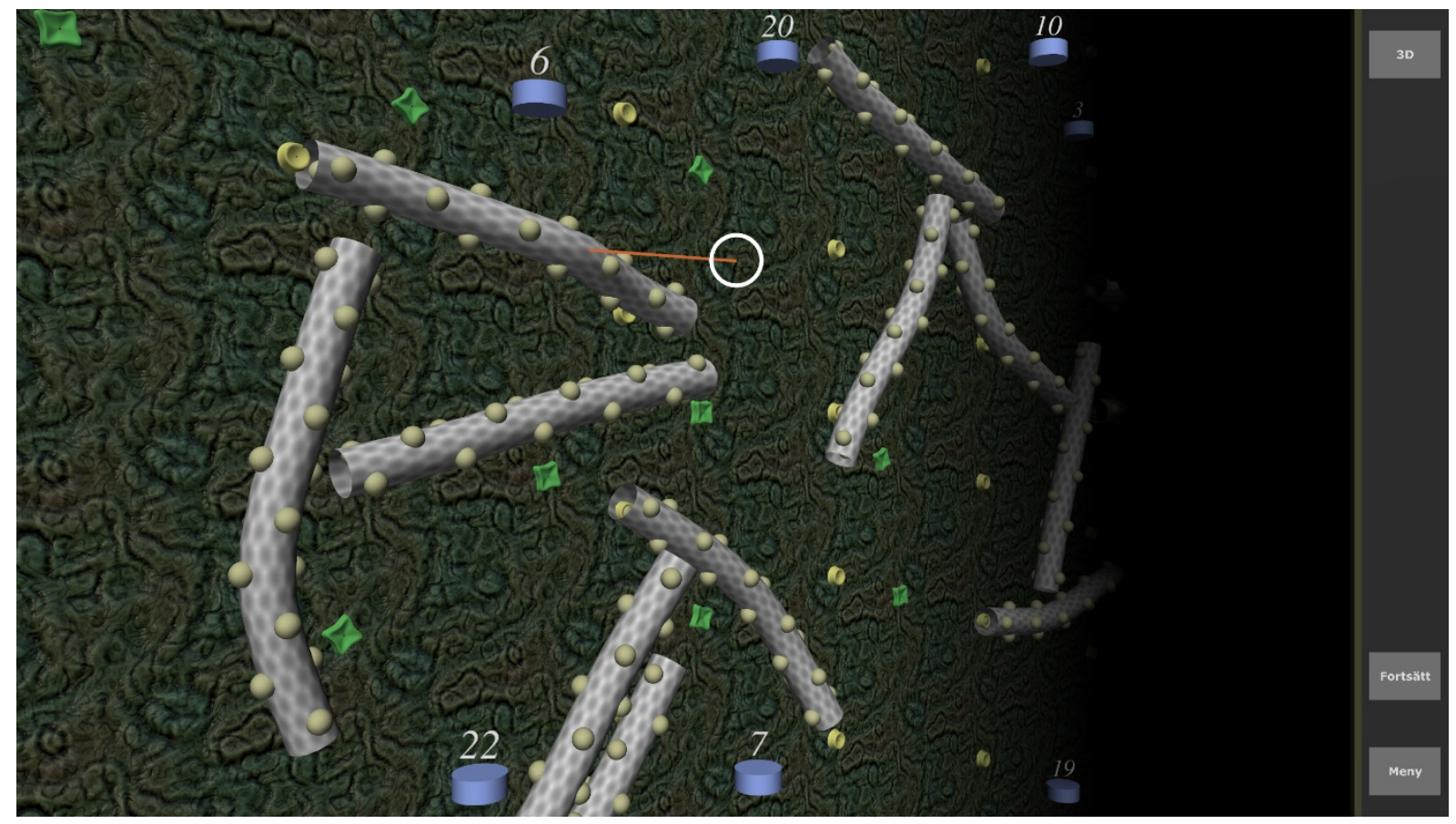

